\title{
Hepatectomy in Robotic Surgery
}

\author{
Danilo Coco $^{1 *}$, Silvana Leanza ${ }^{2}$ \\ ${ }^{1}$ Department of General Surgery, Ospedali Riuniti Marche Nord, Pesaro, Italy; ${ }^{2}$ Department of General Surgery, Carlo Urbani \\ Hospital, Jesi, Italy
}

Edited by: Ksenija Bogoeva-Kostovska Citation: Coco D, Leanza S. Hepatectomy in Robotic Surgery. Open Access Maced J Med Sci. 2020 Sep 20
8(F):215-217. https://doi.org/10.3889/oamjms.2020.470 Keywords: Hepatectomy; Robotic; Surgery Correspondence: Danilo Coco, Department of Genera Surgery, Ospedali Riuniti Marche Nord, Pesaro, Italy. -mail: webcostruction@msn.co Received: 31-Mar-2020 Revised: 14-Aug-2020 Accepted: 18-Aug-202 Copyright: $\odot 2020$ Danilo Coco, Silvana Leanza Funding: This research did not receive any financia Competing Interest: The authors have declared that no competing interest exists Open Access: This is an open-access article distribute under the terms of the Creative Commons Attribution-
nonCommercial 4.0 International License (CC BY-NC 4.0)

\section{Introduction}

The development of robotic surgery in the past three decades has revolutionized liver resection operation. Robotic surgery helps patients in terms of length of hospital stays, estimated loss of blood, length of operation time, costs, conversation rate, and related problems. Conventionally, liver surgery is among the most challenging operations [1]. However, the introduction of robotic surgery has offered a reliable solution for the process for both operators and patients.

\section{Methods}

A PubMed search selected a total of 25 publications related to robotic surgery. Seventeen papers with 235 patients that engrossed on liver resection offered detailed information about the patient. All the researchers incorporated the da Vinci robot system (United States, California, Sunnyvale, and Intuitive) during the study [2]. The researchers conducted the study using PubMed databases with primary search phrases such as robotic liver, robotic hepatic resection, robotic hepatic surgery, and robotic liver resection [2]. The researchers screened all abstracts and titles for review with careful analysis of the data to ensure that there was no double counting of patients [3]. The study analyzed patient demographics (indication for surgery, sex, and age), outcomes (hospital stay, complications, conversion, transfusion requirements, blood loss, and operation time), perioperative characteristics (operating maneuverers), hepatocellular carcinoma (survival, recurrence, and tumor size), and standard oncological outcomes for liver metastasis [4].

\section{Results}

A total of 25 periodicals with 235 patients provided pertinent information to robotic liver surgery. The review included 19 papers with 229 patients that engrossed on liver surgery and offered detailed details about the patient [5]. After sorting double-counted cases, 218 patients were eligible to be included in the research. Nine studies were comprehensive series, with two reasonable journals using conservative open surgery and laparoscopic surgery. Each of the nine studies involved more than 4 patients, contributing 
toward the increased cases in 95.4 (208 patients) who responded in the survey [6]. Two of these case scenarios had four patients each, and there were eight single-case information in the study. Patient's number for every study ranged from 1 to 70 , and all the researchers used the da Vinci robot system (California, Sunnyvale, and Intuitive).

\section{Discussion}

Robotic liver surgery is a new technology involving invasive surgical practice integrating laparoscopic surgeries with distant robotic control of tools and by a support patient and patient-side surgeon. This study entailed reports of around 200 patients who undertook liver resection surgeries [7]. The reported rates of complications and conversion were $20.3 \%$ and $4.6 \%$, respectively, due to underestimation from publication and selection biases [8]. In two comparative studies during the research, the complications rates observed during robotic liver surgery were relevant to those of conventional laparoscopic procedures [9]. The series confirmed that robotic liver surgery was feasible and safe when executed by knowledgeable specialists. Research indicated that the structures of da Vinci robotic such as the usage of three robotic arms by the same operator, the ability to perform intracorporeally, and the use of enunciating tools that can be protected in vascular clams are useful in managing and controlling bleeding without the use of open surgery [10].

The researchers observed that the capability to bolt the surgery enunciating tools to substitute vascular clamping was vital because it offers the anesthesia group time to save life of a patient. However, it is essential to note that the absence of tangible criticism during knot tying with robotic tools and performing suture procedures can lead to uncontrolled overstretching of the tissues, thus causing suture disruption [11]. Careful visual operation is critical during the compensation procedure. Segmentectomy and partial resection were the most commonly executed robotic liver resection surgeries [12]. Besides, right hepatectomy and partial resection had popularity among some patients. However, research revealed that most cases of directly hepatectomy were only conducted in specialized health facilities [13]. The series recorded a high tendency of blood loss during the intraoperative procedure. However, the researchers analyzed the results because the cases did not offer a full representation of the present standard in robotic liver surgery [14], [15].

A team approach comprising of highly skilled operators during the robotic liver section plays a critical role in saving the patient's life. Besides, the exchange and installation of robotic arms require knowledgeable staffs [16]. Adequate training is essential to the usage of robotic surgery tools in health-care facilities. Some researchers have indicated that mastering the robot requires several robotic procedures in laparoscopic surgery [17]. The study analyzed the incidences of robotic liver surgery that have been described in the journal articles. However, the articles selected for the study failed to provide a precise analysis of specific outcomes and patient demographics [18]. The research's summary, particularly the oncological outcomes, was not well represented in all articles on this topic. Most of the materials focused on short-term perioperative outcomes. Future studies should analyze cost-effectiveness and long-term results [19]. The issue of future studies is necessary to investigate the strengths and weaknesses of robotic liver resection before making conclusions about its effectiveness.

\section{Conclusion}

Robotic liver resection is feasible and safe, mainly when used by experienced operators. Expert patient-side surgeons with progressive laparoscopic knowledge are necessary during robotic liver surgery operations. Wristed tools are used in different maneuvers, for example, in suturing bleeding points and looping glissonian pedicles. Long-term outcomes of oncologic procedures are not clear, but short-term perioperative consequences show that the robotic liver is similar to conformist laparoscopic liver surgery.

\section{References}

1. Beard RE, Ocuin LM, Tsung A. Robotic liver resection for malignancies. In: Minimally Invasive Surgery for Upper Abdominal Cancer. Cham: Springer; 2017. p. 327-41. https:// doi.org/10.1007/978-3-319-54301-7_31

2. Chen PD, Wu CY, Hu RH, Chen CN, Yuan RH, Liang JT, et al. Robotic major hepatectomy: Is there a learning curve? Surgery. 2017;161:642-9. https://doi.org/10.1016/j.surg.2016.09.025 PMid:27884614

3. Chen PD, Wu CY, Hu RH, Ho CM, Lee PH, Lai HS, et al. Robotic liver donor right hepatectomy: A pure, minimally invasive approach. Liver Transpl. 2016;22(11):1509-18. https://doi. org/10.1002/lt.24522

PMid:27509325

4. Magistri P, Olivieri T, Assirati G, Guerrini GP, Ballarin R, Tarantino $G$, et al. Robotic liver resection expands the opportunities of bridging before liver transplantation. Liver Transplantation. 2019;25(7):1110-2. https://doi.org/10.1002//t.25477

PMid:31021039

5. Croner RS, Perrakis A, Hohenberger W, Brunner M. Robotic liver surgery for minor hepatic resections: A comparison with laparoscopic and open standard procedures. Langenbecks Arch Surg. 2016;401(5):707-14. https://doi.org/10.1007/ s00423-016-1440-1 


\section{PMid:27207697}

6. Di Benedetto F, Tarantino G, Guerrini GP, Ballarin R Magistri $P$. Robotic surgery in liver transplantation and resection. In: Liver Transplantation and Hepatobiliary Surgery. Cham: Springer; 2020. p. 175-82. https://doi. org/10.1007/978-3-030-19762-9_18

7. Gheza F, Esposito S, Gruessner S, Mangano A, Fernandes E, Giulianotti PC. Reasons for open conversion in robotic liver surgery: A systematic review with pooled analysis of more than 1000 patients. Int J Med Robot. 2019;15(2):e1976. https://doi. org/10.1002/rcs.1976

PMid:30500105

8. Giulianotti PC, Bianco FM, Daskalaki D, Gonzalez-Ciccarelli LF, Kim J, Benedetti E. Robotic liver surgery: Technical aspects and review of the literature. Hepatobiliary Surg Nutr. 2016;5(4):311. https://doi.org/10.21037/hbsn.2015.10.05 PMid:27500143

9. Giulianotti PC, Quadri P. Liver resection: Right lobectomy. In: The SAGES Atlas of Robotic Surgery. Cham: Springer; 2018. p. 335-41. https://doi.org/10.1007/978-3-319-91045-1_29

10. Giulianotti PC, Sbrana F, Coratti A, Bianco FM, Addeo P, Buchs NC, et al. Totally robotic right hepatectomy: Surgical technique and outcomes. Arch Surg. 2011;146(7):844-50. https://doi.org/10.1001/archsurg.2011.145 PMid:21768432

11. Hamad A, Tsung A, Ejaz A. Learning Curve and Pitfalls in Establishing a New Robotic Liver Surgery Program. Columbus, $\mathrm{OH}$, USA: James Cancer Center and Solove Research Institute. https://doi.org/10.21037/ls.2019.09.04

12. Magistri P, Tarantino G, Ballarin R, Coratti A, Di Benedetto F. Robotic liver surgery is the optimal approach as bridge to transplantation. World J Hepatol. 2017;9(4):224. https://doi. org/10.4254/wjh.v9.i4.224

\section{PMid:28217260}

13. Hill CR, McNicoll CF, Kirgan DM. Robotic liver resection. In: Robotic-Assisted Minimally Invasive Surgery. Cham: Springer; 2019. p. 91-9. https://doi.org/10.1007/978-3-319-96866-7_11

14. Kent L, Aydin A, Ahmed K, Jiao LJ, Froghi S. A Systematic Review and Meta-analysis of Robotic Versus Laparoscopic Partial Liver Resection; 2017.

15. Khan S, Beard RE, Kingham PT, Fong Y, Boerner T, Martinie JB, et al. Long-term oncologic outcomes following robotic liver resections for primary hepatobiliary malignancies: A multicenter study. Ann Surg Oncol. 2018;25(9):2652-60. https://doi. org/10.1245/s10434-018-6629-9

\section{PMid:29987604}

16. Khan S, Tsung A. ASO Author reflections: The evolution of minimally invasive liver surgery and the future with robotics. Ann Surg Oncol. 2018;25(3):786-7. https://doi.org/10.1245/ s10434-018-6880-0

PMid:30298328

17. Kingham TP, Leung U, Kuk D, Gönen M, D'Angelica MI, Allen PJ, et al. Robotic liver resection: A case-matched comparison. World J Surg. 2016;40(6):1422-8. https://doi.org/10.1007/ s00268-016-3446-9

PMid:26913732

18. Lai EC, Tang CN. Robotic partial hepatectomy for colorectal cancer liver metastases. In: Colorectal Cancer Liver Metastases. Cham: Springer; 2020. p. 385-95. https://doi. org/10.1007/978-3-030-25486-5_29

19. Lee KF, Fong AK, Chong CC, Cheung SY, Wong J, Lai PB Robotic liver resection for primary hepatolithiasis: Is it beneficial? World J Surg. 2016;40(10):2490-6. https://doi.org/10.1007/ s00268-016-3528-8

PMid:27138884 